\title{
ANALISIS KINERJA PACKET FILTERING BERBASIS MIKROTIK ROUTERBOARD PADA SISTEM KEAMANAN JARINGAN
}

\author{
Ari Muzakir \\ Fakultas Ilmu Komputer, Program Studi Teknik Informatika \\ Universitas Bina Darma \\ Email: arimuzakir@binadarma.ac.id \\ Maria Ulfa \\ Fakultas Vokasi, Program Studi Teknik Komputer \\ Universitas Bina Darma \\ Email: maria.ulfa@binadarma.ac.id
}

\begin{abstract}
ABSTRAK
Pada penelitian ini fokus pada ujicoba kinerja jaringan komputer dari sisi sistem keamanan jaringan. Ujicoba sendiri dilakukan pada jaringan komputer yang ada di Laboratorium Komputer di Universitas Bina Darma menggunakan sistem operasi Mikrotik. Adapun hasil akhir yang diharapkan melalui penelitian ini yaitu untuk melihat secara komprehensif kemampuan packet filtering yang terdapat di mikrotik routerboard dalam mengatasi masalah keamanan jaringan komputer. Keamanan jaringan yang dimaksud adalah kemampuan pada proses pemblokiran URL http dan https. Pada ujicoba yang dilakukan, filtering rule mampu melakukan blok url yang ada pada protocol HTTP maupun HTTPS yang mana membuktikan bahwa kinerja dari filtering rule cukup baik. Dalam menganalisis kinerja packet filtering menggunakan tool network packet anayzer Wireshark dengan cara melakukan capture paket yang lewat didalam jaringan dan menampilkan semua informasi secara detil. Hasil akhir yang didapatkan dalam proses simulasi sistem keamanan jaringan menggunakan wireshark adalah setiap paket yang dikirim tidak dapat dibaca (blokir) baik pada protocol http maupun https. Kinerja dari tools disebuah router mikrotik tidak menjamin keamanan yang baik, efektivitas keamanan tergantung pada kemampuan administrator dalam mengkonfigurasi sebuah keamanan tersebut.
\end{abstract}

Kata kunci: packet filtering; sistem keamanan jaringan; microtik routerboard; analisis kinerja jaringan.

\begin{abstract}
In this research focus on testing the performance of computer networks from the side of the network system. Experiments performed using Mikrotik operating system on a computer network that is in the Computer Laboratory at the University of Bina Darma. The purpose of this program is to find out the filtering capability of the routerboard microtic in solving computer network problems.Network security is the ability to block http and https URLs. In the experiments carried out, the filtering rule is able to block urls that exist in both http and https protocols which prove that the performance of the filtering rule is quite good. In analyzing packet filtering performance using the Wireshark anayzer network packet tool by capturing packets that pass in the network and display all the information in detail. The final result obtained in the network security system simulation process using Wireshark is that each packet sent cannot be read (blocked) on both http and https protocols. The performance of the tools on a microtic router does not guarantee good security, the effectiveness of security depends on the ability of the administrator to configure a security.
\end{abstract}

Keywords: packet filtering; network security system; mikrotik routerboard.

\section{PENDAHULUAN}

Kemajuan teknologi pada saat ini memaksa seluruh jaingan komputer yang ada saat ini untuk mampu menunjukkan bahwa model sistem keamanan terus dianggap masih sangat penting bagi pengguna yang menginginkan suatu keamanan baik dari dalam maupun dari luar jaringan dikarenakan internet merupakan sebuah media jaringan komputer yang memiliki akses sangat terbuka di dunia. Sehingga akibat yang harus ditanggung adalah jaminan keamanan dari pengguna yang terhubung secara langsung kedalam jaringan internet tersebut. Berbagai bentuk serangan bahkan ancaman baik secara langsung maupun tidak langsung akan memberikan dampak pada aktifitas yang terjadi pada jaringan internet tersebut, sehingga utnuk memberikan proteksi terhadap berbagai bentuk kemungkinan terjadi serangan dalam jaringan tersebut maka 
dibutuhkan suatu mode keamanan seperi firewall. Firewall sendiri merupakan konsep dari sistem keamanan yang terdapat pada sistem operasi. Sistem operasi pada suatu jaringan komputer merupakan media pengatur sumber daya yang mana memberikan keamanan atau proteksi pada jaringan tersebut, serta menjadikontrol pengguna untuk selalu dapat tersambung pada sumber jaringan [1]. Sedangkan Firewall dikonfigurasi untuk dapat mencegah akses yang tidak diharapkan kedalam jaringan baik dari dalam maupun luar.

Firewall mempunyai dua komponen penting yaitu router dan application gateway[2]. Router adalah hardware yang mempunyai software sendiri untuk membangun suatu benteng yang menjadi pertahanan untuk jaringan, sedangkan application gateway adalah software khusus untuk mengamati paket yang keluar dan masuk. Kemampuannya dalam menjalankan keamanan terdiri atas packet filtering dan proxy services. Packet filtering merupakan aksi yang dilakukan suatu alat atau software yang secara ketat mengontrol pemilihan aliran dari suatu paket yang berisi informasi yang didapat dari suatu jaringan [3][4].

Pada penelitian ini menggunakan sistem operasi mikrotik. Mikrotik router adalah salah satu sistem operasi yang dapat digunakan sebagai router jaringan yang handal, mencakup berbagai fitur lengkap untuk jaringan komputer. Selain itu Mikrotik dapat juga berfungsi sebagai firewall [2][5]. Melalui penelitian ini akan melakukan analisis kinerja dari sistem keamanan jaringan yaitu packet filtering untuk mengetahui kinerja didalam melakukan pemblokiran akses (url dan domain block). Tujuan dari penelitian ini adalah melakukan perancangan sistem keamanan menggunakan packet filtering sebagai firewall dengan menggunakan mikrotik routerboard, kemudian melakukan analisis kinerja untuk mengetahui kemampuan didalam firewall.

\section{METODOLOGI PENELITIAN}

Dalam menjalankan penelitian ini menerapkan model eksperimen, dimana dimulai dari pembentukan dan pemeliharaan kelompok, kontrol, memberikan keputusan yang terjadi, mengontrol pada setiap faktorfaktor yang relevan, melakukan perubahan yang diizinkan, dan pada akhirnya adalah monitoring terhadap hasil pengukuran tersebut [6]. Adapun penelitian model eksperimen ini dilakukan melalui beberapa tahapan yaitu:

a) Persiapan yaitu melakukan observasi terhadap objek yang akan diteliti, pengumpulan kebutuhan yang berkaitan dengan teori-teori dan konsep, menentukan variabel penelitian, dan membuat desain model.

b) Pelaksanaan yaitu melakukan ujicoba atau penelitian, pengumpulan data-data hasil ujicoba, melakukan analisis sampai pada penyusunan laporan hasil.

c) Kesimpulan yaitu diperoleh hasil akhir dari pengamatan dan ujicoba yang dapat digunakan sebagai bahan keputusan.

\subsection{Analisis}

Sebelum melakukan analisis packet filtering dalam sistem keamanan jaringan, ada beberapa tahap yang akan dilakukan oleh penelitian diantaranya:

a) Konfigurasi router mikrotik dan client sehingga dapat connect ke internet (internet services provider) yang terhubung ke server [7].

b) Konfigurasi router mikrotik untuk menerapkan packet filtering.

c) Melakukan tes perbandingan variabel (URL block dan Domain block) pada packet filtering [8].

\subsection{Perancangan Topologi Jaringan}

Pada penelitian ini peneliti menggunakan peralatan yaitu router, switch, kabel straight, dan 5 personal komputer. Pada penelitian melakukan monitoring secara langsung pada router yang selanjutnya proses implementasi dilakukan pada komputer dengan memakai aplikasi winbox. Pada komputer server serta client akan terkoneksi langsung melalui jaringan intranet dengan subneting yang sama, dan masing-masing komputer client diberi IP addres pada tabel 1 dibawah ini:

Tabel 1. IP Address jaringan LAN pada laboratorium cisco 1

\begin{tabular}{cccc}
\hline No & Nama & IP Address & Subnetmask \\
\hline 1 & Personal komputer $(P C)$ & 192.168.10.2/24 $-192.168 .10 .6 / 24$ & 255.255 .255 .0 \\
2 & Router MikroTik & Gateway: $192.168 .10 .1 / 24$ & 255.255 .255 .0 \\
\hline
\end{tabular}




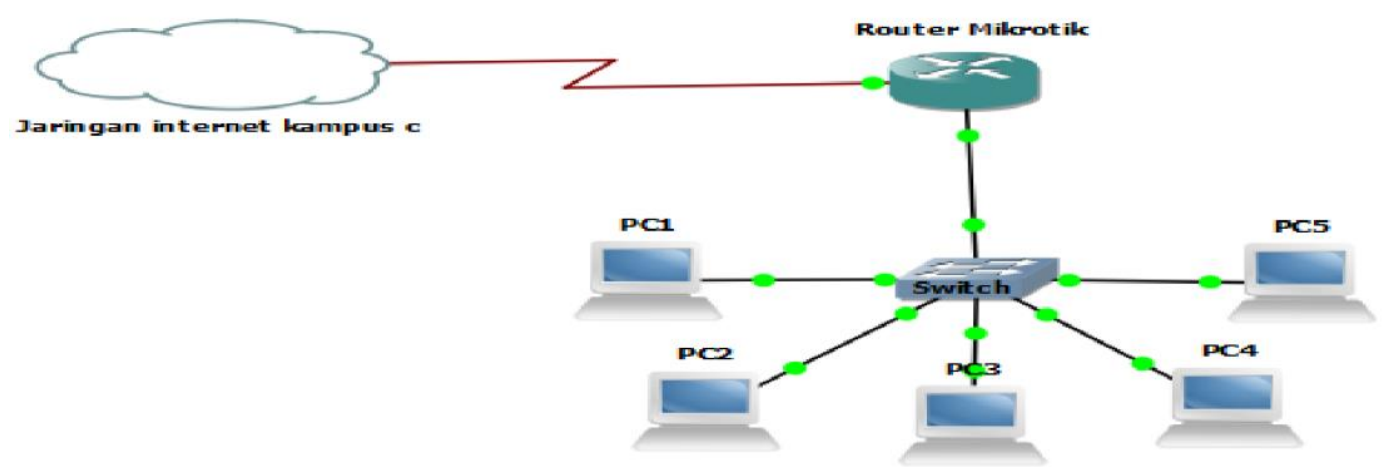

Gambar 1. Perancangan Topologi Jaringan

Pada gambar 1 tersebut menunjukkan bahwa perancangan topologi menggunakan komputer core i3 dengan sistem operasi windows pada Laboratorium Cisco 1 Kampus C Universitas Bina Darma, masingmasing memiliki 25 PC client disetiap ruangan yang terhubung dengan switch dan menggunakan router mikrotik, dimana peneliti hanya menggunakan 5 PC, 1 switch dan router mikrotik sebagai bahan penelitian pada Laboratorium cisco 1.

\subsection{Perancangan Firewall Filtering}

Setiap paket yang memasuki atau meninggalkan jaringan akan dikonfigurasi baik diterima atau ditolak sesuai dengan aturan yang ditentukan oleh pengguna [8]. Packet filtering ini dalam hal transparansi kepada pengguna sudah cukup baik, namun beberapa hal sulit untuk dilakukan konfigurasi. Pada gambar 2 berikut memperlihatkan perancangan dari packet filtering.

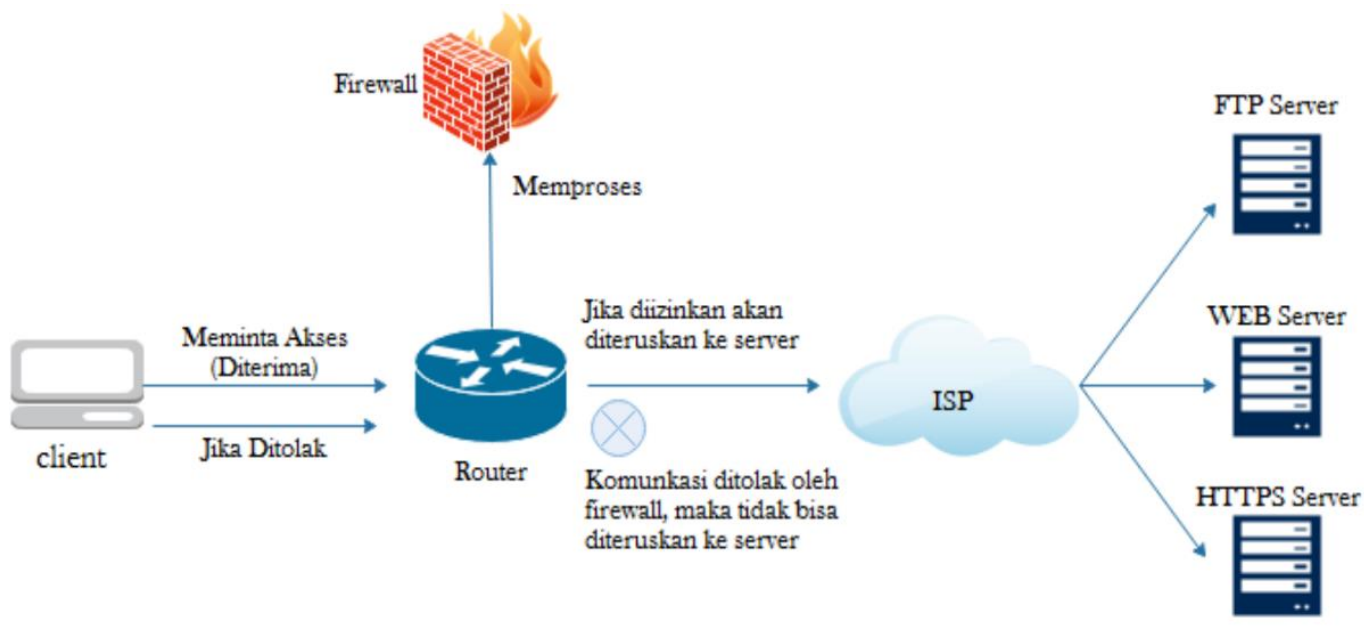

Gambar 2. Perancangan Packet filtering

Untuk mem-block situs-situs yang dirasa tidak diharapkan untuk ditampilkan oleh client seperti facebook, youtube, dan website lainnya, mikrotik sendiri menyediakan fitur acces control list (ACL). Fitur ini berfungsi untuk memberikan akses permintaan atau memblokir traffic dari ip address tertentu dan untuk mengatur traffic berdasarkan source / destination ip address dan port [9]. Dapat dikatakan bahwa ACL sendiri terbukti dapat menangani berbagai kondisi yang terjadi pada firewall. Dengan memasukan ip atau domain website yang ingin di block pada menu layer 7 protocol: contohnya seperti facebook.com, sebuah client tidak dapat mengakses website tersebut. Caranya adalah dengan memasukan script ${ }^{\wedge}$.+(facebook.com).*\$ yang dimana script tersebut bertujuan untuk memasukkan list target yang ingin di block. Berikut ini pada gambar 3 adalah tampilan menu layer 7 protocol . 


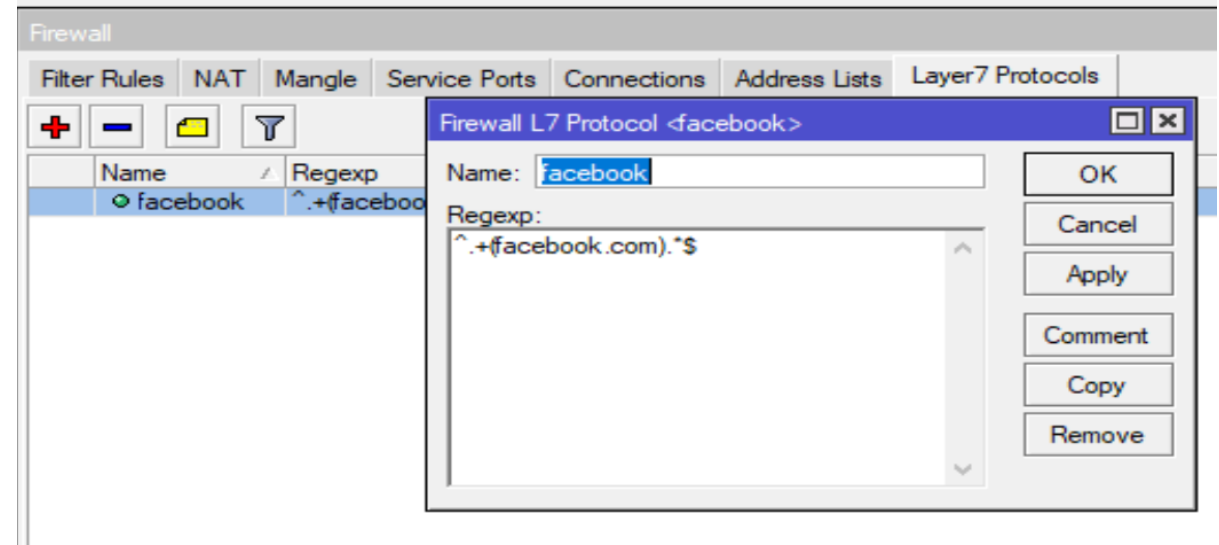

Gambar 3. Ujicoba Menu Layer 7 Protocol

Dari ujicoba pada Gambar 3 diatas, firewall dapat melakukan blocking terhadap website yang telah dimasukkan yang mana untuk selanjutnya adalah melakukan filter rules. Pada filter rules terdapat menu chain yaitu suatu perintah lanjutan untuk mem-block website yang ditargetkan dengan perintah antara lain chain forward, chain input, dan chain oputput [10].

Perintah chain tersebut terdapat di dalam mikrotik yang dapat mem-block atau membatasi hak akses suatu client untuk mengakses website target yang diberi perintah chain tersebut. Berikut ini adalah tampilan dari menu filter rules yang terdapat dalam mikrotik router OS. Setelah perintahh chain diterapkan, maka untuk menjalankan proses selanjutnya adalah dengan melakukan perintah perintah action drop. Perintah action drop adalah perintah yang digunakan untuk membuang paket data yang tersimpan pada client melalui perangkat router. Proses ini dilakukan secara diam-diam agar tidak diketahui, dengan mengirimkan pesan penolakan ICMP (Internet Control Message Protocol), sehingga ketika client mengirimkan pesan ping dari CMD, maka hasilnya adalah request time out (RTO).

\section{HASIL DAN PEMBAHASAN}

Sistem keamanan filtering rule dapat memblokir akses protocol http maupun https serta kinerja sistem keamanan filtering mampu melakukan blokir terhadap beberapa akses ke situs web tertentu.

\subsection{Analisis Kinerja Packet Filtering}

Pada proses analisa sistem keamanan jaringan, firewall bertindak sebagai tempat dilakukannya pemfilteran satu layer yang menerapkan metode firewall packet filtering. Metode ini melakukan filtering paket data berdasarkan parameter yang sudah ditentukan sebelumnya. Cara kerja metode ini berada pada level IP paket data serta membuat keputusan tindakan yang kemudian akan memberikan akses atau menolak. Sehingga metode ini hanya didesain untuk mamp u mengontrol setiap paket data yang lewat berdasarkan alamat asal, tujuan, port yang digunakan serta tipe informasi yang terdapat dalam paket tersebut. IP firewall sangat aman namum dapat mengabaikan sejumlah $\log$ yang mungkin penting.

Network Filter memiliki lima rantai utama yang dapat digunakan yaitu prerouting, postrouting, input, forward, dan output. Setiap paket yang tiba pada iptables akan melalui rantai prerouting. Disini paket akan mengalami perubahan yang sesuai. Dari sini, paket akan masuk ke keputusan routing. Jika paket ditujukan untuk host itu sendiri, maka akan diteruskan ke rantai input, namun jika paket ditujukan untuk host lain, maka paket akan diteruskan ke rantai forward. Paket yang masuk ke rantai input akan diproses oleh host lokal. Jika kemudian ada paket yang keluar, maka paket akan masuk ke rantai output. Paket yang berasal dari forward dan output kemudian akan masuk ke rantai post-routing sebelum akhirnya paket benar-benar meninggalkan host. Ketika paket masuk melewati firewall, paket filter akan langsung menginspeksi header setiap paket, kemudian mencocokan dengan kebijakan dan peraturan yg diterapkan pada paket filter, paket akan lewat jika memang di izinkan, sedangkan paket akan di tolak apabila paket tersebut tidak memenuhi syarat pada paket filter. Pada gambar 4 berikut merupakan contoh hasil setelah diterapkannya pemblokiran akses maka wireshark tidak dapat membaca https yang ip add 157.240.13.35 yaitu facebook.com yang sebelumnya sudah diterapkan pada router mikrotik RB201 1iL-RM, serta hasil pengujian pemblokiran beberapa situs setelah proses konfigurasi dibandingkan dengan sistem keamanan web proxy pada tabel 2 . 


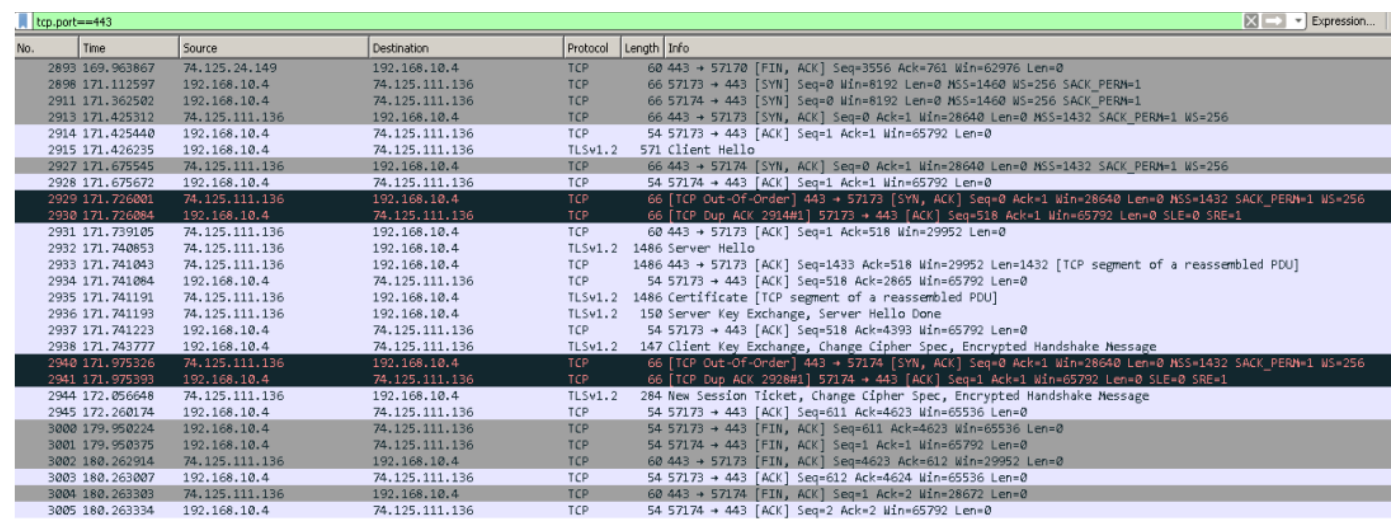

Gambar 4. Hasil Penerapan Pemblokiran Akses Dengan Aplikasi Wireshark

Tabel 2. Hasil Pemblokiran Situs Web

\begin{tabular}{clcc}
\hline No & \multicolumn{1}{c}{ URL (http/https) } & Filtering rule & Web Proxy \\
\hline 1 & yahoo.com & Deny & Deny \\
2 & id.portalgaruda.org & Deny & Deny \\
3 & sisfo.binadarma.ac.id & Deny & Deny \\
4 & youtube.com & Deny & Allow \\
5 & playboy.com & Deny & Deny \\
6 & facebook.com & Deny & Allow \\
\hline
\end{tabular}

\subsection{Pengujian Hasil}

Untuk mengetahui keberhasilan dari beberapa tahapan konfigurasi yang telah dilakukan, maka perlu dilakukan ujicoba. Ujicoba yang dilakukan yaitu pemblokiran url dan domain ada filtering rule dalam sistem keamanan jaringan. Pada gambar 4 dan 5 berikut menunjukkan hasil ujicoba.

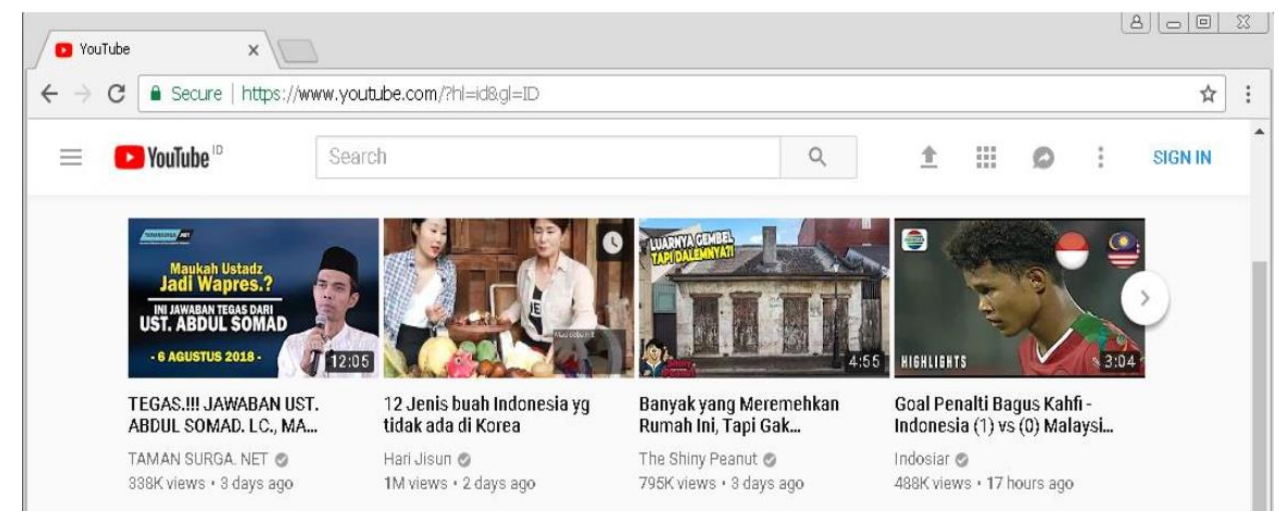

Gambar 4. Akses url dari youtube.com secara normal (tanpa filtering rule )

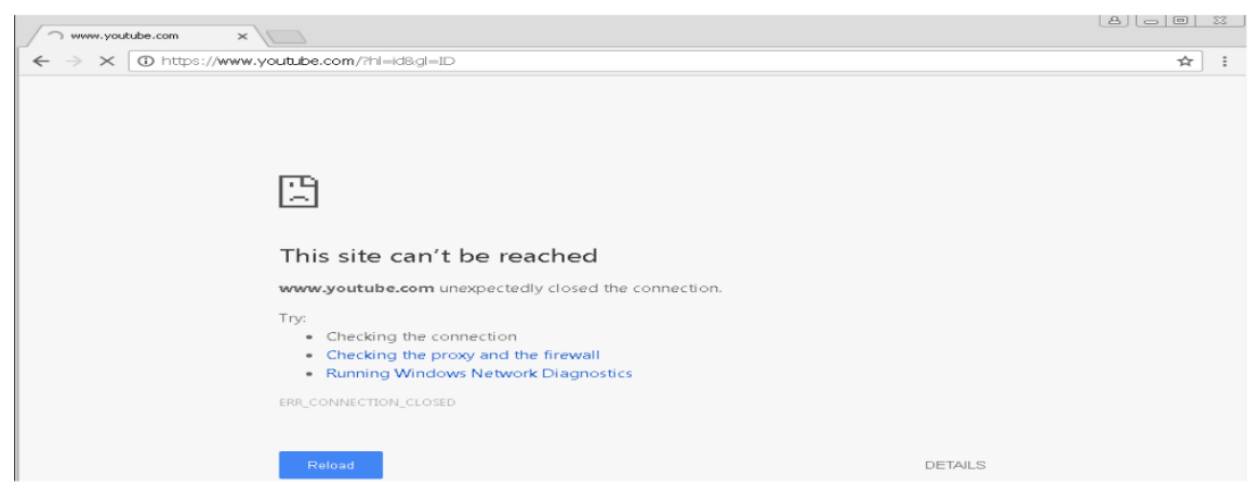

Gambar 5. Akses url dari youtube.com dengan sistem pemblokiran (filtering rule ) 


\section{KESIMPULAN}

a) Adapun tujuan dari penelitian ini adalah untuk mengetahui kemampuan packet filtering dalam melakukan bloking terhadap suatu situs web, kemudian hasilnya adalah metode ini dapat diterapkan untuk sistem keamanan jaringan.

b) Dalam menganalisis kinerja packet filtering menggunakan tool network packet anayzer wireshark dengan cara melakukan capture paket yang lewat didalam jaringan dan menampilkan semua informasi secara detil.

c) Dengan melakukan konfigurasi dan ujicoba sistem keamanan jaringan ini membuktikan bahwa kinerja dari filtering rule cukup baik dalam memblok akses web protocol http dan https.

\section{DAFTAR PUSTAKA}

[1] T. Listyorini and R. Meimaharani, "NETWORKING OPERATING SYSTEM ( NOS ) BERBASIS SIMULASI," J. SIMETRIS, vol. 9, no. 1, pp. 181-188, 2018.

[2] M. Grennan, "Firewall and Proxy Server HOWTO," Linux Doc. Proj., p. 40, 2000.

[3] Rodiah, "Perbandingan Cara Kerja Packet Filtering Dan Proxy Services Sebagai Firewall Pada Keamanan Jaringan," UG J., vol. 6, no. 11, 2012.

[4] J. Boutet, "Use offense to inform defense . Find flaws before the bad guys do.," SANS Inst., 2010.

[5] A. Hikmaturokhman, A. Purwanto, and R. Munadi, "Analisis Perancangan Dan Implementasi Firewall Dan Traffic Filtering Menggunakan Cisco Router," Semin. Nas. Inform., 2010.

[6] A. Muzakir and C. D. Kusmindari, "Design of Push-Up Detector Applications Using Quality Function Development and Anthropometry For Movement Error Detection," Sci. J. Informatics, vol. 5, no. 2, pp. 248-257, 2018.

[7] A. P. N. Permana and R. Firmansyah, "Distribusi Jaringan Menggunakan Routing Ospf," $J$. SIMETRIS, vol. 9, no. 1, pp. 519-532, 2018.

[8] L. H. Chen and W. C. Ko, "Fuzzy approaches to quality function deployment for new product design," Fuzzy Sets Syst., vol. 160, no. 18, pp. 2620-2639, 2009.

[9] P. Silitonga and I. S. Morina, "Analisis Qos ( Quality Of Service) Jaringan Kampus Dengan Menggunakan Microtic Routerboard ( Studi Kasus : Fakultas Ilmu Komputer Unika Santo Thomas S.U)," J. TIMES, 2014.

[10] I. Riadi, "Optimalisasi Keamanan Jaringan Menggunakan Pemfilteran Aplikasi Berbasis Mikrotik Pendahuluan Landasan Teori," JUSI, Univ. Ahmad Dahlan Yogyakarta, 2011. 